\title{
Programs and Measures in the Management of Natural Resources
}

\author{
Radhika Kapur* \\ Pedagogy and Organizational Culture in Nursery Schools, Delhi University, New Delhi, India \\ *Corresponding Author: Radhika Kapur, Pedagogy and Organizational Culture in Nursery Schools, Delhi University, New Delhi, India.
}

Received: July 15, 2019; Published: August 19, 2019

DOI: 10.31080/ASAG.2019.03.0620

\begin{abstract}
In not only India, but in other countries of the world as well, it is necessary to manage the natural resources in an appropriate manner. The natural resources are regarded as assets to the individuals and nation. In India, the individuals, primarily belonging to rural and tribal communities are dependent upon the natural resources to a major extent for the sustenance of their living conditions. In rural communities, there is scarcity of water and individuals need to depend upon the water bodies for the sustenance of their living conditions. Hence, it is of utmost significance for them to ensure to keep the environment clean and free from various forms of pollution. In addition, when the rural and the tribal individuals are making use of natural resources, they need to ensure, they do not exploit them. In other words, individuals need to generate awareness in terms of measures and programs that are necessary to make efficient use of natural resources and preserve the environmental conditions. The main concepts that have been taken into account in this research paper include, status and management scenario of natural resources, exploitation of natural resources, measures for the management of natural resources, and programs for the management of natural resources.
\end{abstract}

Keywords: Environment; Exploitation; Management; Measures; Natural Resources; Programs

The natural resources are regarded as assets of human beings. Their survival depends upon natural resources. The three main kinds of natural resources are, soil, water and vegetation. From a comprehensive perspective, land, water, biodiversity, genetic resources, biomass resources, forests, livestock, fisheries, and flora and fauna are considered as natural resources. Natural Resources Management (NRM) refers to the sustainable utilization of main natural resources, such as, land, water, air, minerals, forests, fisheries, and wild flora and fauna. Together these resources provide the ecosystem services that underpin the existence of the individuals. In rural and tribal communities, the individuals are depended upon natural resources to a major extent for their survival. They need to be aware that natural resources should not be exploited and preserved well. The individuals should not overuse the natural resources [1].
In the field of adult education, the individuals are provided with information in terms of management of natural resources. The main reason being, natural resources are an integral part of the lives of the individuals and render an effective contribution in facilitating their existence. The concern for natural resources management and providing information to the students in educational institutions have been developed for various reasons. These are, over-exploitation of natural resources by the growing population, destruction of vegetation has resulted in land degradation, denudation, soil erosion, landslides, floods, draught and unbalanced ecosystems. A balanced ecosystem is a crucial need for the survival of the individuals. Natural resources such as, land, soil, water, biodiversity, genetic resources, biomass resources, forests, livestock and fisheries are the foundation of human resources, affluence and progress. There has been degradation of these resources to a rapid extent, therefore, it 
is essential for the individuals to formulate measures to preserve them [1].

The demographic and socio-economic pressures notwithstanding the unmindful agricultural intensification, over use of marginal lands, imbalanced use of fertilizers, organic matter depletion and deteriorating of soil health, extensive diversion of agricultural lands due to non-agricultural uses, misuse of water, salination of fertile lands and water logging, loss of biodiversity, genetic erosion and changes in the climatic conditions are the primary causes for the degradation of natural resources. Natural resources provide the fundamental life support in the form of both consumptive and public good services. Ecological processes maintain soil productivity, nutrient recycling, cleaning of air and water and climatic cycles. The natural resources foundation is coming under the increasing pressure from both increasing population and higher levels of per capita economic activity [1]. The preservation of natural resources is essential for not only survival of human resources, but also for progression of the communities and nation as a whole.

\section{Status and management scenario of natural resources}

The natural resources, such as, land, water, biodiversity, genetic resources, biomass resources, forests, livestock and fisheries are the ones, which facilitate the survival of human beings. Some natural resources such as, soil, air and water and various components are cycled repeatedly in nature. When there are occurrence of any types of environmental problems, the individuals feel helpless to make any changes. One of the important aspects that needs to be taken into account in the status and management scenario of natural resources is, the individuals should be aware of making use of them in an appropriate manner and conserving the environment. Apart from international laws and regulations to lead to the protection of the environment, there are national laws as well for environmental protection. There are national and international organizations protecting the environment [2]. The status and the management of natural resources have been taken into consideration in terms of various resources, which have been stated as follows: [3]

\section{Land}

Land is the most important natural resource for the survival of the individuals. In India, of the total cultivated land, 40 percent is irrigated and the remaining is rain-fed. The land distribution is skewed to a major extent. More than 80 percent of the farmers are small, marginal, sub-marginal and together own about 40 percent of the total cultivated land. In addition, the increasing proportions of the holdings are turning out to be uneconomical. There is a deterioration in the soil health, especially in terms of the micro-nutrient deficiencies and the fast depleting carbon content, resulting in low and decelerated TFP growth rates.

Water

Water availability at the National level is reaching close to 1700 cubic metre, per capita the threshold line. India annually receives about 350 million hectare metre rain water, but almost half of it finds its way back into the sea. Whereas, the per capita water storage within the country is only 210 cubic metres. Besides low water usage efficiency, there is inequity in the utilization of water use and irrigation development. The water management strategies have been recommended as follows:

1. Undertake scientific and comprehensive assessment of water resources, monitor and evaluate water extraction, storage and use and enhance income per unit of water consumed.

2. Prevent and discourage unsustainable use of groundwater resources in critical zones, develop the resources in unexploited zones and increase awareness among the farmers and other stakeholders in terms of the value and scarcity of water and negative outcomes of inappropriate utilization.

3. Develop and adopt the water use efficient and cost-effective and eco-friendly crops, cropping patterns, farming systems and technologies.

4. Integrate rain surface and ground-waters and promote conjunctive use of inappropriate quality and polluted waters.

5. Institutionalize participatory management of water (Water User's Associations, including proactive women's participation), rationalize water pricing and operational and maintenance charges and distribution of irrigation water and equitable access to water as a common resource.

\section{Biodiversity and agriculture genetic resources}

The loss of biodiversity and agriculture genetic resources has brought about improvements in the genetic vulnerability of the agricultural systems, besides losing invaluable gene-pools, such as, Tharparker in Western Rajasthan. The two recent national initia- 
tives in this field, namely, the National Biodiversity Board, Plant Variety Protection and Farmer's Rights Authority are supposed to address this issue, but there is less co-ordination between the two. Participatory breeding, integrated germ plasm and indigenous knowledge conversation and benefit sharing, particularly involving women and tribals, should be promoted through the transparent modes of accessing the National Gene Fund and increasing gene and IPR literacy.

- $\quad$ Forests: Forests are regarded as the natural resources for agriculture, primary production and rural economic growth. India harbouring 16 major forest types, tropical, temperate, alpine and so forth is one of the 17 mega diversity centres and two biodiversity hotspots of the world. Per capita forest area within the country is one-tenth of that of world average and 41 percent of the forest cover of the country is degraded. Despite the high importance of forests as the source of food, fodder, fuel and fibre, and of linking conversation with the community based forestry, allocation to the forestry sub-sector has been meagre, i.e. less than one percent of the plan size. Through the watershed system, the Joint Forest Management (JFM) should be changed to Community Forest Management (CFM) and the concerned committees in collaboration with the Watershed Committees, should ensure maintenance of the forest profile through large scale tree plantations, deploying close to 140 thousand staff, trained in natural resource management.

- Livestock: Livestock accounts for about 27 percent of the agricultural GDP, and is positively egalitarian in its distribution and ownership by women. Livestock is regarded as the major source for income, food and employment security. Possessing the World's largest livestock population, India ranks first in the production of milk, fifth in the production of eggs and seventh in the production of meat. Total livestock has been increasing at a much higher rate of 3.6 percent per annum, against only 1.1 percent registered for the crops sub-sector during the past decades. The targeted agricultural annual growth rate of 4.1 percent during the XI Plan is stipulated to be achieved through a growth rate of about eight percent in the livestock sub-sector. There is a need to endorse institutional supports and policy actions, such as, livestock insurance, market and price support, Livestock Feed and Fodder Corporation, Fodder Banks, Small Holder's Poultry Estates and so forth are needed towards achieving rapid and inclusive growth.
- Fisheries: Fisheries account for about 53 percent of the production from aquaculture and contribute effectively to food security, nutrition, employment and economic securities and fortunately are one the rapidly growing agricultural sub-sectors during the past three decades. Presently, fisheries contribute 4.6 percent of the total GDP, provide employment security to about 11 million individuals and annually earn the foreign exchange of worth Rs. 7300 crores. It is about one-fifth of the value of the National Agricultural Export. The overall growth rate of fish production could be doubled to about eight percent towards achieving the overall agricultural growth rate during the XI plan. The newly established National Fisheries Development Board among other things should support in a strong manner, Integrated Coastal Zone Management and Aquarian Reforms are also suggested by NCF.

\section{Exploitation of natural resources}

Exploitation of natural resources has a direct impact upon the livelihoods of poverty stricken individuals. During the past decade, considerable achievements in decentralizing the management of natural resources have been made and number of initiatives have also been put into operation [4]. Natural resources have been a subject of conflict. Land is the primary rural asset and the resource for promoting better livelihoods of the individuals. It is now subject to competing demands from agriculture, industry and urban development. Land is a resource which forms the basis of the sustenance of the living conditions of the individuals. When the states have made use of land for different purposes, number of individuals have lost their livelihoods without adequate compensation and resettlement. Forests have been a major concern, which has given rise to conflicting situations. The mineral resources in India are located in forested areas and the exploitation of these resources leads to disruption of livelihoods and displacement of the forest dwelling tribal communities. The alienation of tribal communities have mostly taken place due to deforestation [5].

Water has also been a source of disputation [5]. As it is comprehensively understood that water has been one of the essential requirements of the individuals to survive. Hence, they not only need to maintain natural resources, but also ensure that water that is particularly used for drinking purposes is clean and pollution free. The increasing industrial and urban demands in water are often met by sourcing water from the rural communities. In this manner, rural communities usually experience scarcity of water and clean drinking water. The rural individuals are dependent upon the wa- 
ter bodies and wells to obtain water. In some cases, due to their unawareness, they even dump waste materials and cause pollution of water bodies. The pollution of water bodies is not only unfavourable for the individuals, but may affect the aquatic life as well. Therefore, there have been implementation of measures and programs mainly in rural communities to generate awareness among individuals in terms of preservation of natural resources and keeping the environment and water bodies free from pollution.

Rural agrarian livelihoods are dependent upon the natural resources to a major extent. But exploitation and degradation of resources has led to negative effects upon the lives of the individuals. The severe degradation of land is the major concern and 57 percent of total land area has been degraded on account of environmental and man-made reasons. These include, soil erosion, loss of vegetation, over-use of chemicals in agriculture and intensive cultivation. In India, there has been prevalence of water shortage, which has affected the lives of the individuals in all communities to a major extent. The individuals are not even having access to safe drinking water. In such cases, the only alternative that is available is obtaining water from the water bodies. The pressure on natural resources has put a great amount of stress on the countryside with deep economic consequences and high degree of social and political discord [5].

The exploitation of natural resources are mostly done by tribal communities. These communities are residing in hilly and mountainous regions and are mostly dependent upon the natural resources. Agriculture is the major occupation of these communities, but apart from agriculture, they are also engaged in the production of handicrafts and artworks. For this purpose, they obtain wood and other materials from the natural environment. In order to treat their wounds, illnesses and other health problems, they obtain herbs and medicinal plants from the forests. For satisfying their nutritional requirements, these individuals get engaged in activities, such as, fishing, hunting and gathering. Therefore, utilization of natural resources is done for multiple purposes. But in the present existence, there have been transformations taking place and tribal communities too have generated awareness in terms of the measures and programs that exploitation of natural resources should be alleviated, and the environmental conditions should be kept clean and pollution free.

\section{Measures for the Management of Natural Resources}

The measures for the management of natural resources have been stated as follows: [1].

- Irrigation: Irrigation methods are used in the agricultural sector to provide water in the fields. In the past, farmers used to make use of small irrigation channels to carry water to their fields. These go from the source of water along the slopes to the fields. Pipes are made use of to avoid seepage losses. By means of gravitational force, they transport irrigation water from the source. In hills, it is difficult to construct the small irrigation channels for all the terraces and pipes are convenient for transporting water. To make effectual use of water, they use a sprinkler system through gravitational force and economical utilization of water. In the present existence, there has been utilization of modern and innovative methods that are enabling the farmers to provide water to their fields. Hence, the farmers are able to preserve the natural resources through utilization of modern irrigation methods.

- Water Harvesting: The regions, which experience a high degree of rainfall and lack the proper management system, in those areas, most of the water gets wasted as a runoff. In the regions, where the rainfall is high, it is essential for the individuals to adopt the measures, where water is not wasted. Farmers and agricultural labourers make use of traditional methods in order to harvest rainwater. These are making use of small ponds. Several ponds are constructed at various places and the water is used for survival or supplemental irrigation. In this manner, the individuals are able to save rainwater and make effectual use of it. Improvements in the traditional practices that are there at the bottom LDPE sheets are placed to check seepage losses. Lined tanks are cost-intensive and beyond the reach of the farmers. The measures, which are formulated by the farmers to save rainwater has proved to be beneficial to them to a major extent.

- Management of Drinking Water: Drinking water is an essential requirement for all individuals, therefore, it is vital for them to manage drinking water. In the management of drinking water, the individuals need to be aware of two major aspects, these are, keeping the water clean and storing it in a safe place. In the Himalayas, streams are the source of water and farmers consider them important. The water is used for drinking purposes as well as they make efforts to keep the streams free from pollution. They maintain vegetation on the banks of the streams to have a clean flow without sediment for human consumption. The cattle is not permitted on the places from where 
drinking water is to be collected. The individuals, belonging to rural and tribal communities, have their own systems of the management of drinking water. The drinking water should be clean as contaminated water can cause major health problems and illnesses.

- Water-based Industry: In the hilly regions, flour mills are not available. Farmers adopt indigenous technologies to operate flour mills by means of waterfall. The home-made wooden wheels, called turbines are used to operate the mills. It is the local response to the needs of the individuals with electric or any other complex machine systems. In rural as well as in urban communities, individuals are employed in industries and factories. This is apparent that in the manufacturing and production processes, the individuals need to make use of water. Therefore, it can be stated that not only flour mills require water, but other industries also need water. Therefore, it is vital for the individuals, belonging to all communities to generate awareness in terms of preservation of water resources. The water bodies need to be kept clean and free from pollution.

- Agricultural Sector: In rural areas, agriculture is regarded as the primary occupation of the individuals. In the agricultural sector to promote productivity and profitability, it is vital for the individuals to make efficient use of natural resources. The farmers, who make use of traditional methods make use of special type of traditional plough. Other types of ploughs do not work in the hilly regions, as the soil is gravelly and not deep. Under the rain-fed conditions, farmers in the hilly regions plough their land several times, before the onset of rain to conserve water and increase the water retention capacity. The farmers and the agricultural labourers need to generate awareness and be well-quipped with the production systems. In rural communities, there have been establishment of training centres, which are providing information to the farmers and agricultural labourers in terms of modern, scientific and innovative methods. The utilization of modern and innovative methods would lead to an increase in productivity. Furthermore, the farmers also generate awareness in terms of management of natural resources.

- Curbing Pollution: There are various forms of pollution, which have led to depletion of natural resources and the environmental conditions have also experienced detrimental consequences. The various forms of pollution are, air, water and land. Air pollution is caused due to omission of gases and smoke from industries, factories and vehicles. Water pollution is caused due to throwing of waste materials into the water bodies. Land pollution is caused by dumping of waste materials into the land and making the surroundings unclean. It is essential to curb various forms of pollution for management of natural resources, survival of human beings and development of the nation. The individuals, belonging to rural, tribal and urban communities need to ensure, they do not throw waste materials into the water bodies or on the land. On the other hand, the industries and factories need to ensure that they do not omit gases into the air, which may cause air pollution. The individuals need to get their vehicles checked and make sure they do not cause air pollution. Curbing pollution is one of the important factors in the management of natural resources and preservation of the environment.

- Capacity Building: The individuals need to build their capacities and get engaged in the implementation of tasks and activities, which may lead to preservation of the environment. For instance, the job of construction of roads, bridges, dams and other infrastructure requires capacity building. These tasks require the individuals to develop manual skills and abilities and they need to work diligently and resourcefully. In order to build capacity, the individuals need to get enrolled in training centres to acquire efficient understanding in terms of various aspects. They need to be well-equipped with techniques and methods that are required to implement the tasks in the suitable manner. The individuals need to focus upon capacity building on a continuous basis. As with advancements taking place, they need to be well-equipped with technologies and other innovative methods that are needed to generate the desired outcomes.

- Promoting Sustainable Development: In rural communities, the individuals are mainly residing in the conditions of poverty and backwardness. They are struggling to make ends meet and experience number of challenges in promoting sustainable development. In order to promote sustainable development, the individuals are not only required to focus upon alleviation of poverty and backwardness, acquiring education and employment opportunities and generating a source of income to sustain ones living conditions adequately, but they also need to implement measures for the preservation of the environmental conditions and management of natural resources. When the individuals are promoting sustainable development, they need to be aware of factors that are required to manage the natural resources in an appropriate manner. In mainly rural and tribal communities, as individuals are unaware and residing in the conditions of poverty and backwardness, hence, the lack of sustainability on their part would be a primary impediment, which would lead to problems in the management of natural resources. Hence, promoting sustainable development will be one of the factors that would facilitate management of natural resources.

Citation: Radhika Kapur. "Programs and Measures in the Management of Natural Resources". Acta Scientific Agriculture 3.9 (2019): $132-139$. 
- Use of Technologies: The individuals employed in the agricultural sector and farming practices need to make use of cost-effective and appropriate technologies. The development and adoption of water use efficient and cost-effective crops, cropping patterns, farming techniques, modern irrigation methods, and other technologies would render an important contribution in enhancing agricultural productivity and profitability. Integrate rain, surface and ground waters and conjunctive use of poor quality and polluted waters is managed through technologies. Furthermore, it is essential to institutionalize the participatory management of water. Waters Users Associations, including proactive women's participation rationalize water pricing and operational and maintenance charges, distribution of irrigation waters and equitable access to water as a common resource. The utilization of technologies have not only facilitated increase in productivity and profitability in the agricultural sector, but the individuals are also making use of them in leading to management of natural resources. When technologies are made use of, the individuals need to ensure, they are well-equipped with them.

- Prevent Misuse and Exploitation of Resources: Research has indicated that in some cases, the individuals make overuse of resources. In other words, they obtain resources, more than what is required. For instance, wood is utilized for number of purposes. In order to obtain wood, trees are cut down and this leads to deforestation. Therefore, there is a need to initiate programs and generate awareness among individuals in all communities that they should curb deforestation and prevent misuse and exploitation of resources. From the water bodies too, the water should be obtained only to the extent of what is required. The conditions of poverty, illiteracy and unawareness are the major causes that enable individuals to make use of resources, more than what is required. Therefore, when the individuals will make effective use of resources and prevent misuse and exploitation, they will be able to manage natural resources appropriately.

Programs for the management of natural resources

The programs for the management of natural resources have been stated as follows: [6].

- Watershed Management Program: Watershed Management Program in wastelands render a significant contribution to food security and conservation of the environment and natural resources in a participatory mode. The initial phase of the implementation of the project make provision of substantial economic benefits to the participating members. It was primarily the involvement of the donor agency, which brought the individuals in the water- shed together. Once the complete implementation phase was over, the owners of large lands tried to extract more benefits, as they focused upon taking care of their own needs and requirements. The Village Watershed Committee became nonoperational and could not succeed in keeping the individuals, belonging to all categories united for the cause of watershed and long-term benefits. As a result of which the benefits, which emanated from the Watershed Management Program, were no longer put into operation. Hence, it was recommended that the Village Watershed Management Program should be reinforced.

- Water Governance Reforms: Various conceptual frameworks of the water governance reforms and the experiences in the water governance over the past two decades within the country indicates a piece-meal approach akin to the coping strategies rather than aiming at identifying the solutions to water governance issues. The major focus should be put upon the aspect that individuals should make sufficient use of water resources and not misuse or cause their pollution. Research has indicated that individuals have rendered a significant contribution in the cleaning of water bodies. The river Ganges, which is regarded as the lifeline of millions of Indians and the most sacred river of India is stated to be polluted to a major extent. The major causes of pollution of Ganges is, lack of technical expertise, poor environmental planning and lack of support from religious authorities. The initiation of water governance reforms have put major emphasis upon the aspect that water bodies, lakes and rivers within the country should be free from pollution.

- National Bamboo Mission: National Bamboo Mission will promote the growth of the bamboo sector within the country through area-based regionally differentiated strategies. Bamboo Plantation Activities over the next five years would generate about 50.4 million man days of work. It is a centrally sponsored scheme, initiated in 2006-2007 with 100 percent assistance. In order to achieve the objectives of the mission, it is necessary for the states to alleviate the restrictions and barriers that are taking place within the course of development of bamboo.

- Need-based Cropping Systems: The introduction of needbased cropping systems and models in the hills of north-east India, having the ability to conserve soil, moisture and nutrients be introduced, instead of the intensive farming systems, use of high yield varieties of seeds, planting of trees, green hedges, adoption of crop farming models and bamboo based agro-forestry program have been introduced. It is recommended that research-based technologies need to be incorporated in the management of forest resources. 
- Clean Development Mechanism (CDM): As the name implies, $\mathrm{CDM}$ is the program that primarily focuses upon maintaining clean environmental conditions. A variety of new climatic finance mechanisms, using international emissions trading markets are expected to emerge to attract private investments in the mitigation activities in developing countries. The government needs to initiate policies and programs, which would enable the individuals to make use of natural resources in an effectual manner and keep the environment clean. Clean environment is not only enriching for the individuals, but also for animals, birds and plants. It is essential to support the CDM by sectoral and policy crediting mechanisms.

- Disaster Management Programs: Disasters and natural calamities such as, droughts, floods, earthquakes takes place in regions. Due to their occurrence, immense loss is caused to natural resources, environmental conditions, property and lives of individuals. The causes for the occurrence of disasters are natural and man-made. They induce a high vulnerability to farmers and agricultural labourers. The individuals even lose their homes, wealthy and livelihoods opportunities. When the disasters are severe, it takes long-term time period for the individuals to recuperate. There have been initiation of disaster management programs, which generate awareness among individuals in terms of the measures, which need to be implemented to minimise the effects of disasters and help individuals to recuperate.

- Government Organizations and Non-Government Organizations: Government and Non-Government Organizations may render a significant contribution in reaching out to the masses for measures to lessen the impact of changes in the climatic conditions by generation of awareness and educational programs at the community level, different sectors of mitigation measures and steps are developed and put into operation to lead to a reduction in emissions. Furthermore, there is a need for the National Forum for suggesting optimum solutions for the fulfilment of specific needs of individuals and communities and for the government policies. One of the important programs that have been initiated is planting of trees and reducing deforestation. In urban communities, the individuals were organizing campaigns and displaying posters, highlighting the significance of planting more trees and spreading greenery.

- Educational Institutions: In not only higher educational institutions, but in pre-schools and formal schools too, students are imparted information in terms of preservation of the environment and management of natural resources. In higher educational institutions, such as, colleges and universities, there have been introduction of lesson plans, which generate awareness among the individuals regarding the management of natural resources. In the present existence, there has been an increase in the enrolment rate of rural individuals. Due to improvements taking place in the infrastructural facilities, the students are migrating to urban communities to get enrolled in higher educational institutions. Within the course of pursuance of academic programs, they are generating awareness in terms of management of natural resources and keeping the environment clean.

- Environmental Management: In the management of the environment, the individuals need to take into account number of aspects. These include, maintaining cleanliness within the environment, implementing measures to curb various forms of pollution, i.e. air, water and land, planting more trees will help in spreading greenery, not dumping any kinds of waste materials in water bodies and land, the individuals should get their vehicles checked on a regular basis, so they do not cause air pollution, the individuals, employed in industries and factories need to ensure that they implement the production processes in a manner, which should not omit gaseous fumes and cause air pollution, and the individuals should not exploit or misuse the resources. Furthermore, environmental pollution should involve prevention rather than control. It should involve not only conservation, climate change and productivity, but also spirituality. The mix of environmental protection of natural resources and the energy to make use of them is one of the crucial aspects of promoting sustainability.

- Information and Communications Technologies (ICTs): As it has been comprehensively understood that ICTs, are not only significant in enhancing the system of education and promoting development of other organizations and agencies. But individuals are generating awareness in terms of ICT in the management of natural resources and preservation of the environment. In providing solutions to the changes in the climatic conditions, ICTs can render a significant contribution. Millions of television sets, computers, tablets and other technologies are not turned off completely during the night time in homes and offices and can cause global warming. However, ICT can also play a major role in providing solutions by focusing upon the efforts on more standardized power supplies, batteries, smart devices, and research and development. A clear message on the role of ICT in climate change is required and it needs to be delivered outside the ICT sector.

\section{Conclusion}

Management of natural resources is an important aspect for not only the development of individuals and communities, but nation as a whole. The individuals, belonging to rural and tribal commu-

Citation: Radhika Kapur. "Programs and Measures in the Management of Natural Resources". Acta Scientific Agriculture 3.9 (2019): $132-139$. 
nities are the ones, which are dependent upon the natural environmental conditions to a major extent for the sustenance of their living conditions. Hence, there is a need to formulate programs, policies and laws, which have the major objective of managing the natural resources and preserving the environment. The status and the management of natural resources have been taken into consideration in terms of the resources, these are, land, water, biodiversity and agriculture genetic resources, forests, livestock and fisheries. The exploitation of natural resources have a direct impact upon the individuals, belonging to rural and tribal communities. They are primarily residing in the conditions of poverty and backwardness and make use of natural resources to generate a source of income and promote better livelihoods opportunities. They need to be made aware of programs and policies that are needed to preserve the environmental conditions and manage natural resources.

The measures for the management of natural resources are, irrigation, water harvesting, management of drinking water, waterbased industry, agricultural sector, curbing pollution, capacity building, promoting sustainable development, use of technologies and prevent misuse and exploitation of resources. The programs for the management of natural resources are, Watershed Management Program, Water Governance Reforms, National Bamboo Mission, need-based cropping systems, Clean Development Mechanism (CDM), Disaster Management Programs, Government Organizations and Non-Government Organizations, educational institutions, environmental management and Information and Communications Technologies (ICTs). The initiation of these programs and systems have rendered an important contribution in generating information among the individuals, belonging to all communities. The individuals, residing in urban communities also need to be aware in terms of these measures, make use of natural resources in an appropriate manner and prevent exploitation.

\section{Bibliography}

1. Natural Resource Management. (n.d.).

2. Chapter 16. (n.d.). Management of Natural Resources.

3. Report of the Working Group on Natural Resources Management Eleventh Five Year Plan (2007-2012). Government of India Planning Commission (2007).

4. Sjoblom D and Rai A. "Natural Resource Management in India". Background Study for the Swedish Country Strategy for India 2003-2007" (2003).
5. India Rural Development Report 2012-2013. (2013). IDFC Rural Development Network.

6. Managing Natural Resources - IDSAsr Verdict. (n.d.). Management of Natural Resources and Environment of India.

\section{Volume 3 Issue 9 September 2019 \\ (C) All rights are reserved by Radhika Kapur.}

